\title{
Design como estratégia de potencialização do artesanato local: estudo de caso da Associação dos Artesãos da Meia Praia
}

\author{
Design strategy for potentialization of local handcrafs: Meia Praia Artisans \\ Association's case
}

RAMOS, Marcos Roberto; Doutorando em Design; UFSC - Universidade Federal de Santa Catarina; marcos.roberto@univali.br

DELFINO, Tayller Costa; Bacharel em Design Gráfico; UNIVALI - Universidade do Vale do Itajaí; tayllercd@edu.univali.br

FURTADO, Bruna Franciely; Acadêmica de Design Gráfico; UNIVALI - Universidade do Vale do Itajaí; bruna.furtado@edu.univali.br

\begin{abstract}
Resumo
A aplicação do design no âmbito do artesanato tem se mostrado uma estratégia para potencializar a identidade dos empreendimentos a fim de obter valorização do meio, transmitindo seriedade e qualidade. Assim, este trabalho tem como principal objetivo apresentar a importância do planejamento e processos do design na estrutura de uma marca, revelando-o como bom aliado e fator influenciador para geração de renda. A partir de uma pesquisa exploratória, aplicada, qualitativa utilizando-se de procedimentos técnicos como pesquisa de campo e ferramentas como mapa conceitual desenvolveu-se um projeto de identidade que valorizasse o trabalho manual desenvolvido na Associação dos Artesãos de Meia Praia - Itapema - SC. Os resultados obtidos mostram a colaboração do design no que se refere ao desenvolvimento de uma identidade visual da entidade e concepção de material para promoção e divulgação.
\end{abstract}

Palavras Chave: design, estratégia, trabalho manual, identidade.

\begin{abstract}
The application of the design in the scope of craftsmanship has shown to be a strategy to enhance the identity of the enterprises in order to obtain value of the medium, conveying seriousness and quality. Thus, this work has as main objective to present the importance of planning and design processes in the structure of a brand, revealing it as a good ally and influencing factor for income generation. From an exploratory, applied, and qualitative research using technical procedures such as field research and tools as a conceptual map, an identity project was developed that values the manual work developed by the Meia Praia Artisans Association - Itapema - SC. The results show the collaboration of the design with regard to the development of a visual identity of the entity and design of material for promotion and dissemination.
\end{abstract}

Keywords: design, strategy, handwork, identity. 


\section{Introdução}

O artesanato é tradicionalmente uma formação de caráter familiar e econômico, na qual o produtor domina completamente as etapas de trabalho, desde o estudo de matéria-prima até os acabamentos finais. Conforme a pesquisa de Informações Básicas Municipais, do Instituto Brasileiro de Geografia e Estatística (IBGE), a atividade se faz presente em 78,7\% dos municípios brasileiros, movimentando aproximadamente $R \$ 50$ bilhões por ano. (IBGE, 2014)

Contudo, a dificuldade no planejamento e gestão de produção tende a prejudicar a atividade artesanal no mercado, visto que o público consumidor está cada vez mais exigente. Dessa forma, é essencial proporcionar a ele novas experiências, investindo tanto no processo criativo quanto na gestão de Design e identidade corporativa permeando o desenvolvimento do projeto inicial até a embalagem, a fim de agregar valor ao produto e torna-lo um diferencial no mercado.

Assim, a partir de um diagnóstico de Design desenvolvido pela Of. Design (Oficina Acadêmica de Design) e ITCP (Incubadora tecnológica de Cooperativas Populares), ambos empreendimentos vinculados à UNIVALI - Universidade do Vale do Itajaí, pode-se levantar diversos fatores possíveis de intervenção na Associação dos Artesãos da Meia Praia - Itapema. Questões pertinentes à identidade corporativa como desenvolvimento e gerenciamento da marca e a valorização de aspectos dos produtos desenvolvidos, serão trabalhadas para proporcionar diferencial competitivo.

\section{Procedimentos Metodológicos}

Para desenvolvimento do projeto trabalhou-se com uma pesquisa de natureza aplicada, abordagem qualitativa, objetivos exploratórios e descritivos utilizando-se de procedimentos técnicos como pesquisa bibliográfica, documental e estudo de caso (GIL, 2010). Para organização do processo de Design trabalhou-se com a metodologia proposta por Frascara (2000) distribuida nas seguintes etapas:

\section{Quadro 1 - Metodologia proposta por Jorge Frascara

Etapas

1. Primeira definição do problema

2. Coleta e Organização de dados

3. Análise e interpretação de dados

4. Segunda definição do problema

5. Determinação de objetivos

6. Terceira definição do problema

7. Desenvolvimento do anteprojeto

8. Apresentação para o cliente

9. Produção e implementação

10. Avaliação dos resultados

Fonte: adaptado de Frascara (2000) 
Assim, a pesquisa foi distribuida em 2 momentos: inicialmente realizou-se o levantamento de banco de dados, livros, revistas e artigos acadêmico-científicos e documentos institucionais referentes à associação dos artesãos, onde neste material de apoio foi possível conhecer conceitos e teorias através do ponto de vista de seus autores, valores relativos a pesquisas nacionais e exemplos reais de projetos realizados publicados. Com base neste desenvolvimento, parte-se para o segundo momento da pesquisa, o estudo de caso, que demonstra a aplicação das estratégias de Design no estabelecimento.

\section{Fundamentação Teórica}

\subsection{O papel do Design}

Geralmente, o primeiro contato entre uma marca e seus consumidores se dá através de estímulos visuais, por meio de diversos pontos de contato, sejam eles impressos ou digitais. Apresentar um design inadequado pode causar dúvidas a respeito da qualidade dos serviços ou produtos oferecidos pela marca, o que pode levar ao desinteresse do público.

Para Martins (2006), todas as organizações precisam dar aos consumidores sinais gráficos que Ihes garantam referência, principalmente, porque nenhuma instituição é igual a outra, assim devem caracterizar diferenças. Deve-se tratar a marca como atividade complexa, que compreende muito mais que os nomes ou produtos. É preciso gerir o negócio em linha com os compromissos da organização com seu meio.

Nesse contexto, um design estrategicamente posicionado e bem executado é capaz de criar um diferencial competitivo para o negócio, pois consegue atribuir valor tanto aos produtos, como embalagens e estabelecer uma comunicação sólida da marca. Dessa forma, o design surge como fator decisivo e determinante na trajetória para o fortalecimento de um nome.

\subsection{O empreendedorismo no artesanato}

A economia solidária é uma organização social de desenvolvimento local que se expande em diferentes comunidades. Para os autores Melo Neto e Froes (2002), o empreendedorismo social é um modelo de desenvolvimento social e sustentavel capaz de suportar o surgimento de novos empreendimentos cooperativos caracterizados pelo aumento da participação dos membros da comunidade em ações locais, no estímulo de novas ideias sustentáveis, resultando na melhoria de qualidade de vida.

O termo artesanato refere-se a toda atividade que resulta em objetos produzidos manualmente ou com a utilização de meios tradicionais, com habilidade, qualidade e criatividade. A atividade surgiu pela necessidade de encontrar soluções práticas para problemas recorrentes do cotidiano, bem como forma de expressão (SEBRAE, 2015).

Em meados dos anos 90, nasceram as ITCPs (Incubadoras Tecnológicas de Cooperativas Populares), pertencentes a universidades públicas e privadas que surgiram para dedicar-se ao movimento da população de baixa renda em cooperativas com apoio jurídico, administrativo e pedagógico (ITCP, 2010).

A incubadora da Universidade do Vale do Itajaí - ITCP/UNIVALI foi criada em 2008, caracterizando-se como programa institucional de extensão universitária, com o intuito de favorecer o desenvolvimento do empreendedorismo social auto gestionário. A ação envolve a incubação de redes e empreendimentos de base social, como cooperativas, associações, feiras e grupos solidários orientados pelos princípios da economia solidária (ITCP, 2010). 
Em Itapema (SC), a Associação de Artesãos da Meia Praia (AAMP), situada no Mercado Público do município e integrantes da incubadora, é um grupo composto por quatorze tipos de artesanato diferentes. Contudo, foram observados aspectos passíveis de intervenção a partir de uma abordagem de Gestão Estratégica de Design, tais como: falta de planejamento, identificação e padronização, pouca divulgação, poucas informações sobre a associação e seus objetivos, o nome que usavam não representava o grupo como um todo, o espaço físico não oferecia estrutura adequada para todos os trabalhadores, os produtos eram distribuídos de forma desigual, entre outros.

Com o apoio do programa institucional, identificou-se a necessidade da inclusão do Design com o propósito de profissionalizar a marca, melhorar o posicionamento e a divulgação da mesma pois o local onde estão situados é pouco frequentado pela população em geral. Identificou-se, também, a necessidade de mudanças no espaço físico alinhadas ao projeto de identidade visual de marca.

\section{Diagnóstico}

O trabalho foi realizado através de reuniões, onde a equipe da Of. Design deslocava-se até a ITCP, situada no município de Itajaí/SC e, também, através de e-mail. Para a apresentação final da proposta desenvolvida, contando com a presença dos membros da Associação de Artesãos da Meia Praia, no município de Itapema/SC, onde obteve-se a aprovação do material.

A seguir, serão apresentados os principais pontos fracos analisados em reuniões com a associação e o caminho pré- estabelecido pela equipe para solucionar tais problemas.

Tabela 1 - Destaque de pontos negativos e soluções cabíveis.

\begin{tabular}{|c|c|}
\hline Dificuldades & Possíveis soluções \\
\hline Falta de planejamento e identificação; & $\begin{array}{l}\text { Desenvolvimento de identidade visual corporativa, a fim de } \\
\text { profissionalizar e padronizar; }\end{array}$ \\
\hline $\begin{array}{l}\text { Situação atual não representa todos os } \\
\text { membros e tipos de atividade de } \\
\text { artesanato; }\end{array}$ & Unificar categorias, ao invés de segmentá-las; \\
\hline Pouca visibilidade; & Aperfeiçoamento de pontos de contato; \\
\hline Local pouco frequentado; & Melhorar a sinalização; \\
\hline $\begin{array}{l}\text { Poucas informações sobre a associação, } \\
\text { membros e objetivos; }\end{array}$ & $\begin{array}{l}\text { Concepção de material impresso contendo informações concretas e } \\
\text { claras a respeito do serviço prestado, incluindo o item anterior } \\
\text { (sinalização); }\end{array}$ \\
\hline $\begin{array}{l}\text { Espaço físico não adequado, produtos } \\
\text { distribuídos de forma desigual. }\end{array}$ & $\begin{array}{l}\text { Parceria com Design de interiores, a fim de redesenhar e melhorar a } \\
\text { estrutura física. }\end{array}$ \\
\hline
\end{tabular}

Fonte: autores (2018)

Assim, com base neste diagnóstico parte-se para a etapa de desenvolvimento do projeto de Identidade. 


\section{Processo de Desenvolvimento}

Após a análise de caso, seguindo as etapas propostas por Frascara (2010), foi estudado pela Of. Design um plano estratégico para melhorar as ações envolvendo a marca. Alguns materiais foram definidos como prioritários. Entre os materiais a serem desenvolvidos estão: uma identidade visual unificada, de forma que represente todos os membros envolvidos e um folder que deve conter informações concretas e claras a respeito da associação, onde estão localizados e quais os tipos de serviços e/ou produtos que oferecem.

\subsection{Identidade Visual}

A identidade corporativa pode ser expressa nos nomes, símbolos, cores e ritos de passagem dos quais as organizações utilizam para distinguirem a si mesmas, em direção as necessidades dos seus públicos. Até um certo ponto, os elementos gráficos possuem a mesma finalidade dos símbolos religiosos ou brasões de família, pois transmitem um sentimento de propriedade e propósito, encorajando a lealdade de seus consumidores ou cidadãos, formando associações duradouras (MARTINS, 2006).

Neste sentido, no estudo de caso deste projeto levou-se em consideração principalmente a referência do trabalho manual, abrangendo todas as categorias de trabalho, sem segmentar um tipo específico de artesanato. A identidade representa a todos através de suas características em comum, como a forma da mão, por exemplo.

Tratando-se de estética, para a definição tipográfica, é comum a utilização de fontes com estilos delicados e orgânicos para esta temática de projeto, pois não causa desconforto visual e traz a sensação de suavidade. As cores transmitem a criatividade nas confecções, a qualidade, a responsabilidade e o cuidado que cada artesão expressa ao seu público consumidor em cada peça produzida.

Em posse destes princípios, o processo de desenvolvimento iniciou com a produção de painéis de referências visuais, com o intuito de servir como inspiração.

Figura 1 - Painel de referências visuais para desenvolvimento de logotipo.
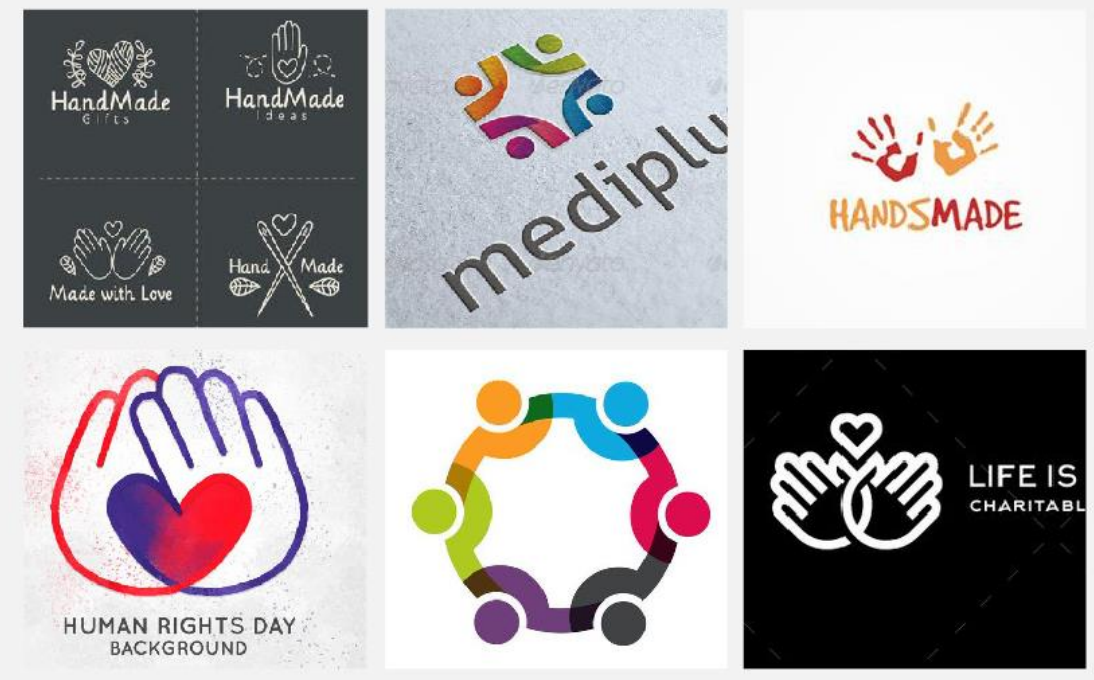

Fonte: Pinterest (2018). 
Seguindo esta inspiração visual o desenvolvimento da marca inicial com a combinação dos conceitos, de forma que atue de maneira multisetorial, uma marca que quando aplicada, represente todas as modalidades de artesanato presentes na associação.

Figura 2 - Primeira proposta do logotipo Associação dos Artesãos da Meia Praia

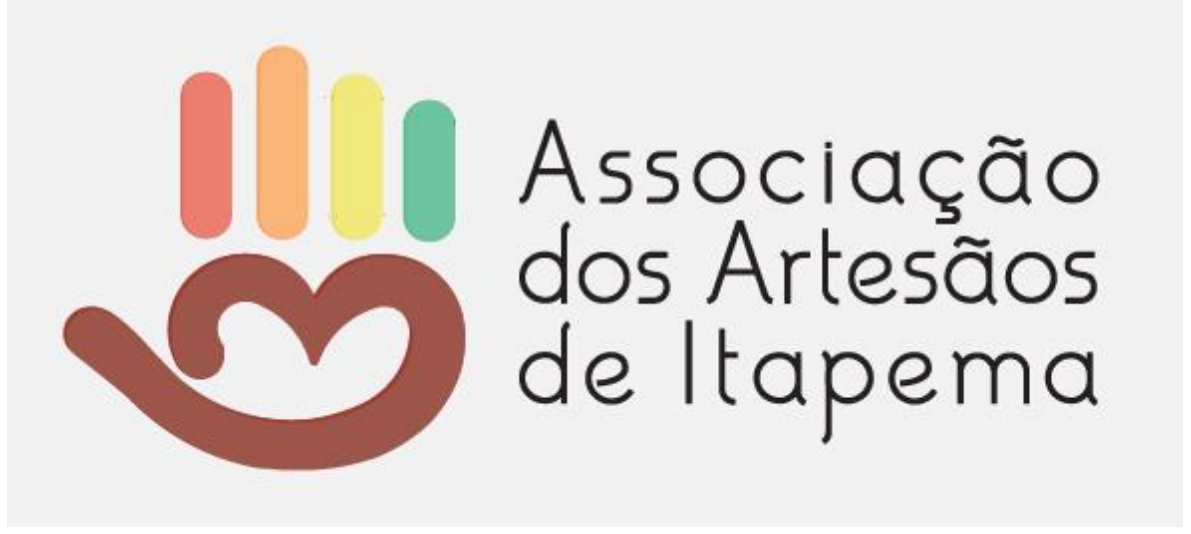

Fonte: Autores (2018).

Analisando-se esta alternativa em conjunto com a parceira ITCP, alguns detalhes foram levantados quanto à cores, efeitos utilizados e principalmente a questão da tipografia que teria que representar o trabalho manual e ao mesmo tempo não seria recomendado uma tipografia com dificuldades em sua aplicação. Também foi sugerida uma alteração na nomenclatura (alterando de Itapema para Meia Praia). Após estas considerações obteve-se o seguinte resultado.

Figura 3 - Versão final do logotipo Associação dos Artesãos da Meia Praia.

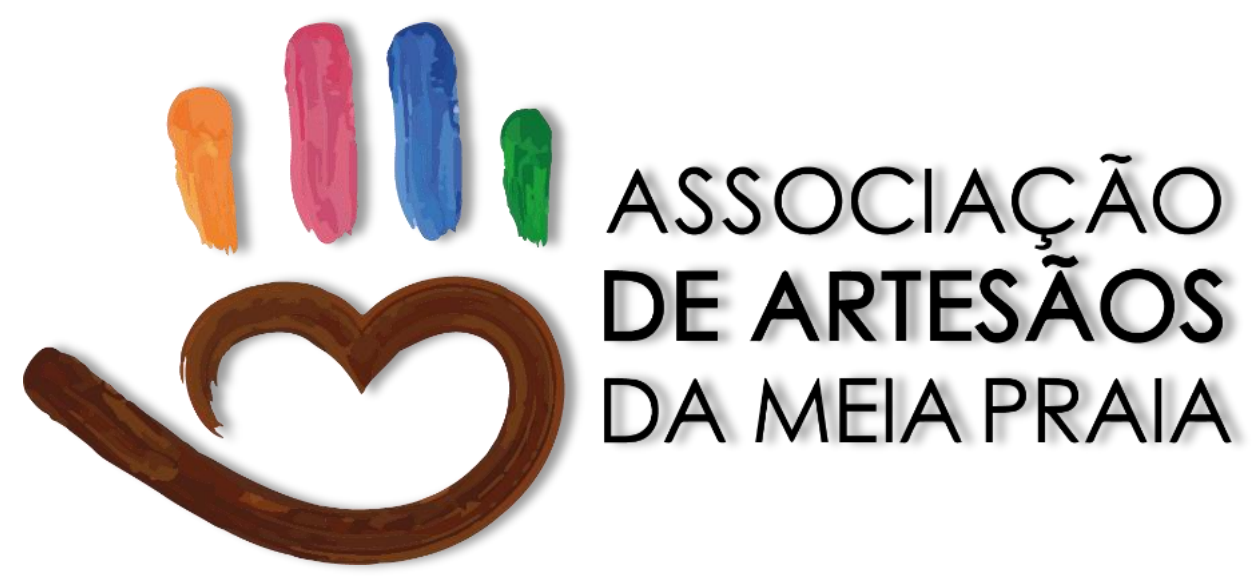

Fonte: autores (2018)

$\mathrm{Na}$ apresentação da segunda alternativa, podemos observar mudanças tais como: a tipografia passou a ter estrutura geométrica, sem a presença de serifa, com estilo moderno e funcional; as cores foram melhor adaptadas aos conceitos que precisam transmitir e, o estilo do traço tornou-se assimétrico, orgânico e mais natural, como pinceladas.

Em apresentação aos associados, o resultado foi bem aceito de maneira com que os mesmos se identificaram com os elementos contidos na peça, gerando um sentimento de pertencimento. 


\subsection{Folder}

Fruto da primeira etapa de projeto, com o desenvolvimento do logotipo viu-se a necessidade de uma peça gráfica que explicasse para o público externo e que servisse também de material para distribuição e divulgação. O folder foi estruturado em duas dobras e teve como conteúdo: apresentação de um breve histórico da associação, informações sobre o trabalho que oferecem, apresentar os membros da associação e cada categoria de trabalho. A linguagem utilizada para este material foi clara e informal.

Figura 4 - Versão final do Folder da Associação dos Artesãos da Meia Praia.

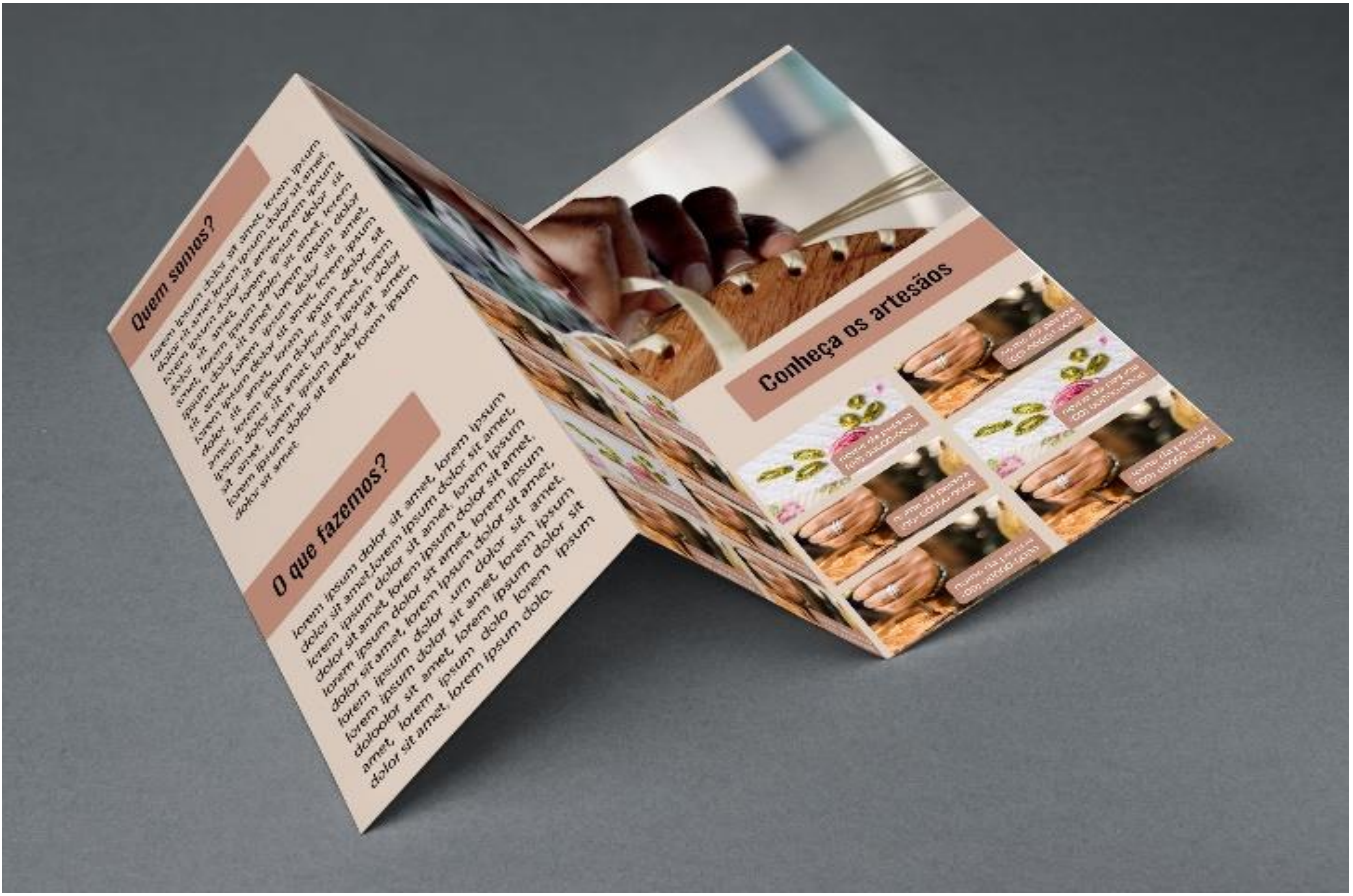

Fonte: Autores, (2018)

Para fins de entrega do proejto, foram definidas estas duas peças como prioritárias: logotipo e folder, e já foram esturturados os elementos visuais como tipografia, cor, elementos gráficos a serem utilizados como guia para desenvolvimento dos demais materiais, posteriormente.

\section{Considerações finais}

Entende-se que a Gestão de Design desempenha um papel fundamental para a valorização dos trabalhos manuais como o artesanato, de modo a atribuir valor aos produtos, aos artesãos e organizações envolvidas neste segmento de mercado. Pode-se afirmar que a gestão, o planejamento e o Design trabalham bem juntos, funcionando como suporte entre si.

Neste estudo de caso real, foi possível evidenciar a importância do Design na relação com o artesanato, apresentando-se como contribuinte para a viabilização do meio, priorizando a diferenciação, divulgação, preço, promoção, esfera em que está inserido, entre outros conceitos de marketing envolvidos e necessários para o desenrolar desse processo. Com os registros apresentados ficam evidentes colaborações por meio de identidade visual e material impresso projetados para a instituição que favoreceram e fortalecerem sua caracterização enquanto Identidade Institucional. 


\section{Referências}

BEST, K. Fundamentos da Gestão de Design. Disponível em < https://books.google.com.br/books ?hl=pt-BR\& $\mid r=\& i d=1-B A J \& o i=f n d \& p g=P A 1 \& d q=$ gest\%C3\%A3o+de+design\&ots=-NKzJxbUOJ\&sig=V aVxbb_AJqjtW4-qYNdZJkX3qDQ\#v=onepage\&q=gest\%C3\%A3o\%20de\%20design\&f=false $>$ Porto Alegre, Bookman, 2012. Acesso em 12 mar. 2018.

EGESTOR. 4 Ps do Marketing: O que são e como funcionam?. Disponível em <https://blog.egestor. com.br/4-ps-do-marketing/> Acesso em 12 mar. 2018.

ENDEAVOR. Das lojas aos maiores marketplaces do país. Disponível em < https://endeavor.org.br /da-loja-shopping-ao-maiores-marketplaces-pais-como-o-olist-se-reinventou-sem-perder-de-vistao-proposito/> Acesso em 12 mar. 2018.

FRASCARA, J. Diseño gráfico y comunicación. 7. ed. Buenos Aires: Ediciones Infinito, 2000. GIL, A. C. 2010. Métodos e técnicas de pesquisa social. 6 ed. 3 reimp. São Paulo: Atlas.

HELLER, E . A Psicologia das Cores: como as cores afetam a razão e a emoção. 1. Ed. 2014. Barcelona: G. Gili, 2012.

IBGE, Instituto Brasileiro de Geografia e Estatística. Pesquisa de Informações Básicas Municipais ano 2014.Disponível em http:// https://ww2.ibge.gov.br/home/estatistica/economia/perfilmunic/ default.shtm/. Acesso em 12 mar. 2018

ITCP, Incubadora Tecnológica de Cooperativas Populares. www.itcpunivali.wordpress.com/sobre/> Acesso em 12 mar. 2018.

MARTINS. J. R. Branding: um manual para criar, avaliar e gerenciar marcas. 3. Ed. 2006. Global Brands. São Paulo.

MELO NETO, F. P.; FROES, C. Empreendedorismo Social. Rio de Janeiro, Qualitymark, 2002 .

MKII. Identidade Visual: a personalidade representativa da empresa. Disponível em http://www. $\mathrm{mk2.com.br/mk2/identidade-visual-a-personalidade-representativa-da-empresa.asp.} \mathrm{Acesso} \mathrm{em}$ 12 mar. 2018

PEQUENAS EMPRESAS, GRANDES NEGÓCIOS. Artesanato atrai empreendedores, falta profissionalização. Disponível em< http://revistapegn.globo.com/empreendedorismo/ noticia/2016/08/artesanato-atrai-empreendedores-mas-falta-profissionalizacao.html> Acesso em 21 mar. 2018.

REVISTA CRIATICA. Evolução do artesanato no Brasil. Disponível em <http://revistacriatica.com. br/evolucao-do-artesanato-no-brasil/> Acesso em 21 mar. 2018

REVISTA OBVIOUS. $O$ artesanato, tradição e memória. Disponível em <http://lounge.obviousmag. org/meus_sete_instrumentos/2015/05/o-artesanato-tradicao-e-memoria.html\#ixzz5BaSlzinS> Acesso em 21 mar. 2018.

SEBRAE. Artesanato e a cultura brasileira. Disponível em <www.sebraemercados.com.br/ artesanato-e-a-cutura-brasileira-a-importancia-da-valorizacao/> Acesso em 03 mar. 2018.

\section{Agradecimentos}

Agradecemos a Associação dos Artesãos de Meia Praia, Incubadora Tecnológica de Cooperativas Populares (ITCP), Universidade do Vale do Itajaí (UNIVALI), Programa UNIEDU PósGraduação e ao Programa de Pós-Graduação em Design (POSDESIGN/UFSC). 